\title{
Comparison of Protein and Peptide Targeting for the Development of a CD169-Based Vaccination Strategy Against Melanoma
}

\author{
Dieke van Dinther, Henrike Veninga, Mirjam Revet, Leoni Hoogterp, Katarzyna Olesek, \\ Joanna Grabowska, Ellen G. F. Borg, Hakan Kalay, Yvette van Kooyk and \\ Joke M. M. den Haan*
}

Amsterdam UMC, Department of Molecular Cell Biology and Immunology, Cancer Center Amsterdam, Amsterdam Infection and Immunity Institute, Vrije Universiteit Amsterdam, Amsterdam, Netherlands

OPEN ACCESS

Edited by:

Bénédicte Manoury,

Institut National de la Santé et de la Recherche Médicale (INSERM),

France

Reviewed by:

Peter M. Van Endert,

Institut National de la Santé et de la

Recherche Médicale (INSERM),

France

Christiane Rued,

Nanyang Technological University,

Singapore

*Correspondence:

Joke M. M. den Haan j.denhaan@vumc.n

Specialty section:

This article was submitted to Cancer Immunity and Immunotherapy,

a section of the journal

Frontiers in Immunology

Received: 14 February 2018

Accepted: 14 August 2018

Published: 06 September 2018

Citation:

van Dinther $D$, Veninga $H$, Revet $M$ Hoogterp L, Olesek K, Grabowska J, Borg EGF, Kalay H, van Kooyk Y and den Haan JMM (2018) Comparison of Protein and Peptide Targeting for the

Development of a CD169-Based

Vaccination Strategy Against

Melanoma. Front. Immunol. 9:1997.

doi: 10.3389/fimmu.2018.01997
$\mathrm{CD} 169^{+}$macrophages are part of the innate immune system and capture pathogens that enter secondary lymphoid organs such as the spleen and the lymph nodes. Their strategic location in the marginal zone of the spleen and the subcapsular sinus in the lymph node enables them to capture antigens from the blood and the lymph respectively. Interestingly, these specific $\mathrm{CD}_{169}{ }^{+}$macrophages do not destroy the antigens they obtain, but instead, transfer it to B cells and dendritic cells (DCs) which facilitates the induction of strong adaptive immune responses. This latter characteristic of the CD169 ${ }^{+}$macrophages can be exploited by specifically targeting tumor antigens to CD169+ macrophages for the induction of specific T cell immunity. In the current study we target protein and peptide antigen as antibody-antigen conjugates to CD169+ macrophages. We monitored the primary, memory, and recall $\mathrm{T}$ cell responses and evaluated the anti-tumor immune responses after immunization. In conclusion, both protein and peptide targeting to CD169 resulted in strong primary, memory, and recall $T$ cell responses and protective immunity against melanoma, which indicates that both forms of antigen can be further explored as anti-cancer vaccination strategy.

Keywords: CD169, Siglec-1, sialoadhesin, tumor immunology, macrophage, T cell, antigen, cross-presentation

\section{INTRODUCTION}

Invasion of pathogens into the circulatory system can result in rapid development of disease. To prevent disease dissemination, the spleen, and lymph nodes sequester microbial, viral, and other nanoparticles from the blood or lymph fluid. In the marginal zone of the spleen and the subcapsular sinus of the lymph nodes, these entry sites are lined with phagocytic cells to trap invading pathogens $(1,2)$. One of the subsets of macrophages present at these locations are characterized by the high expression of CD169, also known as sialoadhesin or sialic acid-binding immunoglobulin-like lectin-1 (Siglec-1). CD169 ${ }^{+}$macrophages produce multiple cytokines and stimulate a variety of innate lymphocytes and together with these cells form a first line of defense after infection (3-7).

Next to their functions in innate immunity, $\mathrm{CD} 169^{+}$macrophages play a central role in the induction of both humoral and cellular adaptive immunity. Antigens captured by CD169 ${ }^{+}$ macrophages are directly presented in intact form on their surface to follicular B cells and thereby 
stimulate germinal center B cell responses (8-13). We and others have observed antigen transfer from $\mathrm{CD} 169^{+}$macrophages to Batf3-dependent classical DCs (cDC1s) which in turn stimulate subsequent $\mathrm{CD}^{+} \mathrm{T}$ cell activation $(14,15)$. This antigen transfer between macrophages and DCs is facilitated by the CD169 molecule which functions as an adhesion molecule for sialylated molecules on DCs and binds strongly to $\mathrm{CDC} 1 \mathrm{~s}$, (16). In addition, $\mathrm{CD}_{169^{+}}$macrophages appear to be able to directly stimulate $\mathrm{CD}^{+} \mathrm{T}$ cells after viral infection (15). As a result, antigen targeting to or infection of $\mathrm{CD}_{169^{+}}$macrophages stimulates strong $\mathrm{CD}^{+} \mathrm{T}$ cell responses that can lead to anti-tumor immunity (14).

Although the application of checkpoint inhibitors has dramatically improved the clinical outcome of several cancer types, most specifically melanoma $(17,18)$, still a significant portion of patients does not benefit from this form of immunotherapy. Since the response to checkpoint inhibitors is related to the presence of an anti-tumor $\mathrm{T}$ cell response, the induction of tumor-specific $\mathrm{T}$ cells by a vaccination approach could potentially increase the number of patients that will respond to the checkpoint inhibitor immunotherapy $(18,19)$. However, the optimal vaccination approach to induce $\mathrm{CD} 8^{+} \mathrm{T}$ cells is not yet established.

Because DCs are crucial for the activation of T cells, several previous experimental approaches focused on the in vitro/ex vivo generation of DCs that loaded with tumor antigens were to be utilized as a cellular vaccine. However, these cellular vaccines are very laborious and have not shown very strong clinical responses so far. In vivo targeting approaches are being developed in which antigens are directed to DCs through antibodies that bind to surface receptors specifically expressed on DCs. Several mouse studies have demonstrated the applicability of this approach for a number of surface receptors on DCs, most notably DEC205 and Clec9A/DNGR-1 (20-23), but (pre)clinical studies in humans are still necessary to determine which markers on (which) human DCs are most optimal for the activation of $\mathrm{T}$ cells. In our previous studies, we have shown that antigen targeting to $\mathrm{CD} 169^{+}$ macrophages result in Ag presentation by DCs and the activation of strong $\mathrm{CD}^{+} \mathrm{T}$ cell responses in mice. In humans, CD169 ${ }^{+}$ macrophages are also found in lymphoid organs and the numbers in tumor draining lymph nodes are positively related to longer survival in cancer patients. (24-28). Therefore, antigen targeting to $\mathrm{CD} 169^{+}$macrophages may form an attractive strategy to activate anti-tumor $\mathrm{T}$ cell responses in humans.

While a number of in vivo targeting studies used whole protein conjugated to antibodies, other studies utilized peptides containing only a CD8 ${ }^{+} \mathrm{T}$ cell epitope $(21,22,29)$. Whole protein contains multiple epitopes to simultaneously induce $\mathrm{CD}^{+} \mathrm{T}$ cells, $\mathrm{CD}^{+} \mathrm{T}$ cell and $\mathrm{B}$ cell responses, while a peptide may only include single epitopes to induce $\mathrm{CD}^{+} \mathrm{T}$ cells and/or $\mathrm{CD}^{+} \mathrm{T}$ cells. Since helper $\mathrm{CD} 4^{+} \mathrm{T}$ and $\mathrm{B}$ cells enhance $\mathrm{CD}^{+} \mathrm{T}$ cell memory responses $(30,31)$, peptide targeting may lead to less than optimal long-term $\mathrm{CD}^{+} \mathrm{T}$ cells responses. However, next to these immunological differences, more practical considerations should also be taken into account. Some melanoma proteins are difficult to produce while a peptide has the advantage that it can easily be synthesized and will allow quicker implementation for future clinical applications. This especially may be advantageous when neoantigens will be used for vaccination. Because of these considerations, it should be determined if a peptide is sufficient to evoke a protective long-term anti-tumor immune response. We therefore compared whether CD169-targeting of whole protein compared to single peptide differed in the induction of specific $\mathrm{T}$ cell responses and subsequent tumor eradication. Our experiments show that peptide targeting is as efficient as protein targeting and could be implemented in a vaccination strategy for melanoma.

\section{MATERIALS AND METHODS}

\section{Mice}

$\mathrm{C} 57 \mathrm{Bl} / 6$ mice were bred at the animal facility of the VU University Medical Center (Amsterdam, The Netherlands). Females between the age of 8-12 weeks were used for the experiments unless indicated otherwise. All mice were kept under specific pathogen-free conditions and used in accordance with local animal experimentation guidelines. This study was carried out in accordance with the recommendations of and approved by the "dierexperimentencommissie" or the "centrale commissie dierproeven.” Batf3 knockout mice were ordered form Jackson and bred in our facility.

\section{OVA And SIINFEKL Conjugates}

Ab-OVA conjugates were produced with SMCC-SATA mediated crosslinking as described previously $(13,14)$. In short, purified antibodies [ $\alpha$ CD169 (MOMA-1), $\alpha$ DEC205 (NLDC-145), and a rat IgG2a isotype control (R7D4)] were functionalized with 5 equivalents of SMCC and endotoxin free OVA (Seikagaku) with 3 equivalents of SATA (N-succinimidyl S-acetylthioacetate, Thermo Fischer Scientific Breda) in phosphate buffer $\mathrm{pH}$ 8.5. Antibodies were desalted over PD-10 columns (GE Life Sciences Eindhoven) against phosphate buffer $\mathrm{pH}$ 7.2, and concentrated with centricon 30 (Merck Millipore Amsterdam) down to 300 $\mu \mathrm{L}$. OVA-SATA was deprotected with $100 \mathrm{mM}$ hydroxylamine hydrochloride (Thermo Fischer Scientific Breda) and desalted over PD-10 columns against phosphate buffer $\mathrm{pH}$ 7.2. After concentration of OVA-SATA with centricon 30 down to $200 \mu \mathrm{L}$, 6 equivalents OVA was added to antibodies while stirring. The antibody-OVA conjugates are incubated at room temperature for $1 \mathrm{~h}$ prior purification over sephadex 75 10/30 column.

Conjugation of SIINFEKL-eahx-lysine(biotin) peptide to antibodies was realized via a sulfhydryl based coupling. Briefly, antibodies were functionalized with 8 equivalents of SMCC [succinimidyl 4-(N-maleimidomethyl) cyclohexane-1carboxylate, Thermo Fischer Scientific Breda] in phosphate buffer $\mathrm{pH}$ 8.5. After desalting over PD-10 columns (GE Life Sciences Eindhoven) against phosphate buffer $\mathrm{pH} 7.2$ activated antibodies were concentrated with centricon 30 (Merck Millipore Amsterdam) down to $500 \mu \mathrm{L}$. 12 Equivalents of peptides in 50 $\mu \mathrm{L}$ DMSO was added to the antibodies and after $1 \mathrm{~h}$ incubation at room temperature conjugates were purified over sephadex 75 10/30 column (GE Life Sciences Eindhoven) according to manufacturer's HPLC settings. 


\section{Immunization}

Mice were immunized i.v. with $1 \mu \mathrm{g}$ Ab:Ag conjugates in the presence of $25 \mu \mathrm{g}$ purified $\alpha \mathrm{CD} 40 \mathrm{Ab}$ (1C10) and $25 \mu \mathrm{g}$ Poly(I:C). On the indicated days after immunization spleens and/ or blood were taken for processing. Boosts consisted of $1 \mu \mathrm{g}$ free SIINFEKL peptide in the presence of adjuvants i.v. 28 days after primary immunization. 7 days after the boost spleens were taken for processing.

\section{Flow Cytometric Analysis}

Single cell suspensions were stained in $0.5 \%$ BSA in PBS for surface markers after blocking Fc receptors with clone 2.4G2. For intracellular staining $0.5 \%$ saponine buffer was used. For macrophages and DC staining spleens were digested with 2WU/ml Liberase TL (Roche Diagnostics) in PBS in the presence of $4 \mathrm{mg} / \mathrm{ml}$ Lidocaine hydrochloride monohydrate (Sigma) and $50 \mu \mathrm{g} / \mathrm{ml}$ DNAse (Roche Diagnostics) at $37^{\circ} \mathrm{C}$. Samples were measured on the Cyan (Backman Coulter) or the Fortessa (BD) and analyzed using FlowJo software (Tree Star).

\section{Intracellular Cytokine Production}

Splenocytes were incubated for $5 \mathrm{~h}$ with $\mathrm{OVA}_{257-264}$ in the presence of GolgiPlug (BD) for CD8 T cells and with OVA $262-276$ overnight with last $5 \mathrm{~h}$ in the presence of GolgiPlug (BD). Cells were fixed in 2\% PFA and stained in saponine buffer for IL-2 and IFNy.

\section{Antibodies for Flow Cytometry And Immunofluorescence}

Antibodies specific for: CD-8a-488 (clone 53-6.7 Biolegend), IL-2-488 (clone JES6-5H4 eBioscience), CD169-488 (clones SER4 and MOMA-1 in house), CD11a-FITC (clone M17/4 eBioscience), CD11c (clone N418 eBioscience), CD44FITC (clone HI44a ImmunoTools), CD11c-PE (clone N418 eBioscience), CD38-PE (clone 90 eBioscience), CD4-PE (clone GK1.5 eBioscience), CD8a-PE (clone 53-6.7 eBioscience), GL7biotin (eBioscience), B220-ef450 (clone 6B2 eBioscience), KLRG1-ef450 (clone 2F1 eBioscience), CD127/IL7R $\alpha-$ APC (clone A7R34 Biolegend), CD8a-APC (clone 53-6.7 eBioscience), IFN $\gamma$-APC (clone xM61.2 eBioscience), CD62LPECy7 (clone MEL-14 Biolegend), CD8a-PECy7 (clone 53-6.7 eBioscience), CD4-PERCPCy5.5 (clone RM4-5 eBioscience), CD8a-PERCPCy5.5 (clone 53-6.7 Biolegend). OVA-488 (Invitrogen). H-2Kb-SIINFEKL Tetramers (LUMC, Leiden). LIVE/DEAD ${ }^{\circledR}$ Fixable Near-IR Dead Cell Stain Kit (Invitrogen) was used according to manufacturers' protocol.

\section{Tumor Experiments}

200,000 B16OVA cells were injected s.c. in $100 \mu \mathrm{l} \mathrm{PBS,} \mathrm{3,} \mathrm{or}$ 7 days later mice were treated i.v. with $1 \mu \mathrm{g} \mathrm{Ab:Ag}$ conjugates in the presence of $25 \mu \mathrm{g}$ purified $\alpha \mathrm{CD} 40 \mathrm{Ab}(1 \mathrm{C} 10)$ and 25 $\mu \mathrm{g}$ Poly(I:C). Tumor outgrowth was monitored by measuring tumor size (length, height, width) 3 times per week using a caliper. Volume of the tumor was calculated using the formula for volume of an ellipsoid $\left(4 / 3 * \pi *\left(\frac{1}{2} \mathrm{l}\right)\left(\frac{1}{2} \mathrm{~h}\right)\left(\frac{1}{2} \mathrm{w}\right)\right)$. Humane endpoints were chosen based on tumor size $\left(\max .1,000 \mathrm{~mm}^{3}\right)$ or general appearance of mice. Tumor cell injection, i.v. vaccination, and tumor measurements were performed blinded, mice were appointed randomly to groups or were distributed according to an equal distribution of different tumor sizes among groups before treatment.

\section{RESULTS}

\section{Efficient Peptide Ag Targeting to CD169+ Macrophages in vivo}

In previous studies we have shown that targeting of ovalbumin (OVA) to CD169 on macrophages can result in T cell responses and that these $\mathrm{T}$ cell responses can reduce tumor outgrowth (14). Here, we compare the conjugation of the immunodominant $\mathrm{CD}^{+} \mathrm{T}$ cell epitope of OVA (SIINFEKL) to the whole protein, OVA, to verify whether a single peptide is sufficient to induce long-term $\mathrm{CD}^{+} \mathrm{T}$ cell responses and to inhibit tumor outgrowth. OVA and SIINFEKL were chemically coupled to specific Abs for targeting to $\mathrm{CD} 169^{+}$macrophages, to $\mathrm{DEC} 205^{+}$ DCs as a positive control or to isotype control Abs $(14,29)$. The functionality and specificity of the CD169- and DEC205specific Abs after conjugation was confirmed by fluorescence microscopy or by flow cytometry (Figures S1A-C). For the induction of immune responses in vivo, mice were immunized with $1 \mu \mathrm{g}$ of the different $\mathrm{Ab}: \mathrm{Ag}$ conjugates in the presence of $25 \mu \mathrm{g}$ anti-CD40 $\mathrm{Ab}$ and $25 \mu \mathrm{g}$ Poly(I:C). We observed a strong induction of $\mathrm{Ag}$ specific $\mathrm{CD}^{+} \mathrm{T}$ cells after both peptide and protein targeting to $\mathrm{CD}_{169^{+}}$macrophages and DEC205 (Figures 1A,B, gating strategy Figure S2A). The isotype control antibody induced low levels of OVA-specific $\mathrm{CD}^{+} \mathrm{T}$ cells as determined by intracellular IFN $\gamma$ production or tetramer staining when compared to non-immunized naive mice (Figure S1D). The induction of specific $\mathrm{CD}^{+} \mathrm{T}$ cells was dose dependent (Figure S1E). As shown recently for OVA targeting to CD169 (16), also the $\mathrm{CD}^{+} \mathrm{T}$ cell responses induced by peptide targeting to CD169 relied on Batf3-dependent cross-presenting dendritic cells (DCs; Figure 1C). As expected only protein targeting induced OVA-specific $\mathrm{CD} 4^{+} \mathrm{T}$ cell and $\mathrm{B}$ cell responses (Figures 1D,E). The T cells activated after targeting either protein or peptide exhibited equal affinity for the SIINFEKL epitope as analyzed using an in vitro titration of the peptide (Figure 1F, Figure S2B). These experiments indicate that both peptide and protein targeting to $\mathrm{CD} 169^{+}$macrophages activate strong, $\mathrm{CDC1}$ dependent, $\mathrm{CD}^{+} \mathrm{T}$ cell responses, while only the protein targeting induced OVA-specific helper $\mathrm{CD}^{+} \mathrm{T}$ cell and $\mathrm{B}$ cell responses.

\section{Targeting of OVA Protein and Peptide to CD169 Results in Efficient Memory T Cell Induction}

$\mathrm{CD}^{+}{ }^{+} \mathrm{T}$ cell responses have been recognized as essential for the maintenance and recall capacity of memory $\mathrm{CD}^{+} \mathrm{T}$ cells $(30,32)$. To test if the absence of OVA-specific $\mathrm{CD} 4^{+}$ $\mathrm{T}$ cell help during the immunization influenced the memory pool of specific $\mathrm{T}$ cells, memory $\mathrm{CD}^{+} \mathrm{T}$ cell responses were analyzed 28 days after immunization. At this time point the immune responses were still clearly measurable and we did 

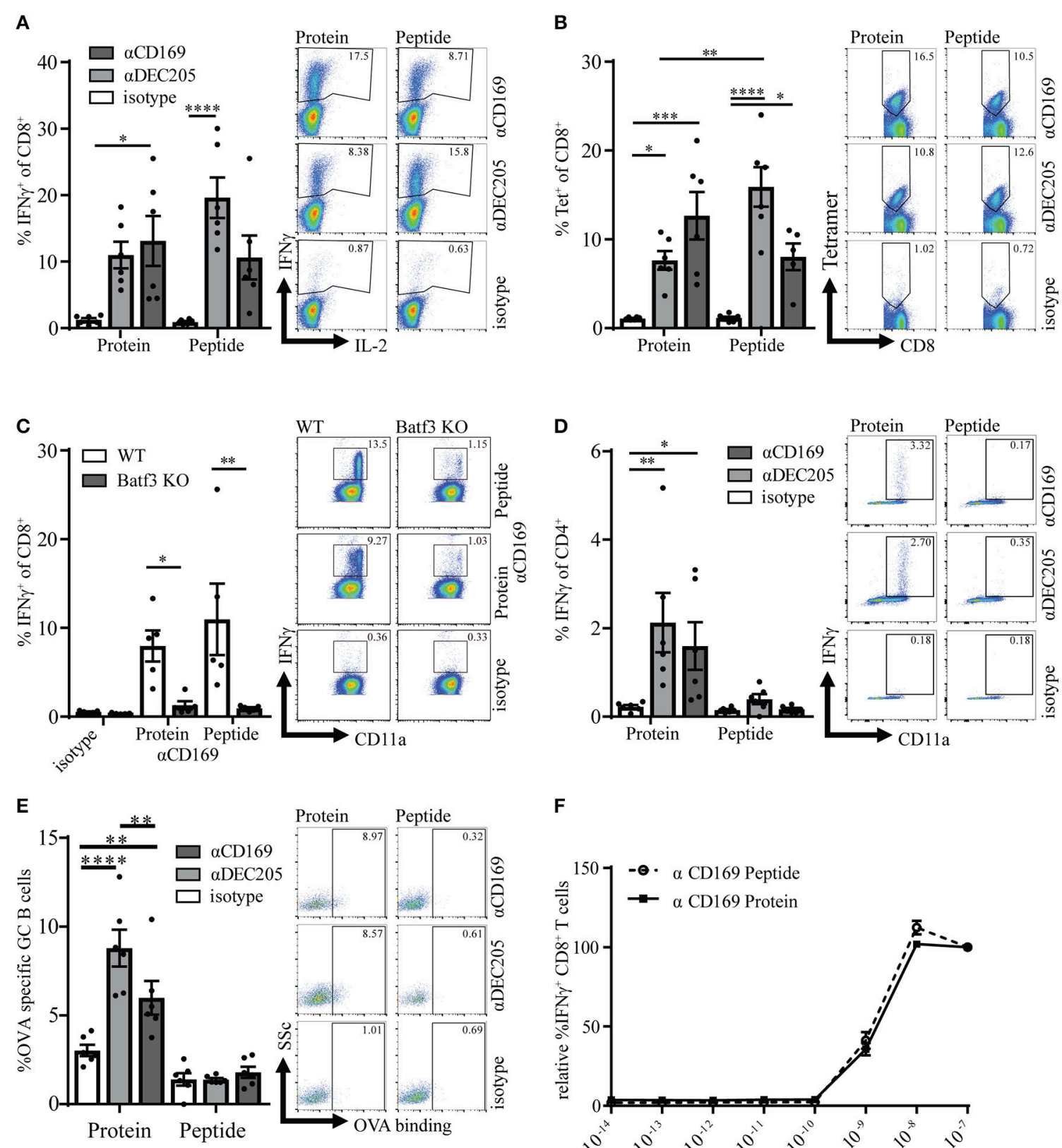

$\mathbf{F}$

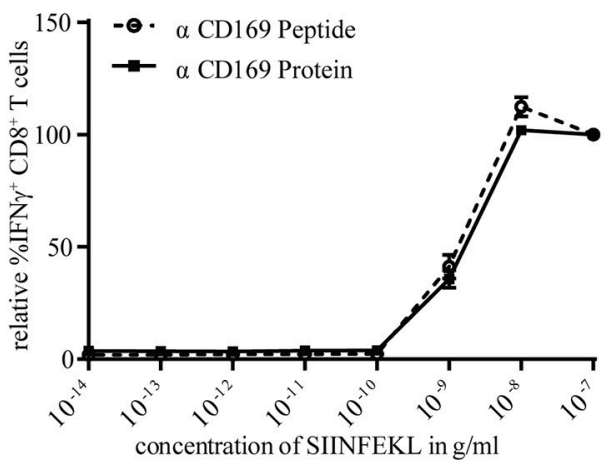

FIGURE 1 | Targeting of protein and peptide to CD169 results in strong primary T cell responses. (A) Percentage of IFN $\gamma$ producing CD8 $8^{+} \mathrm{T}$ cells after $5 \mathrm{~h}$ in vitro restimulation with SIINFEKL 7 days after immunization. (B) Percentage of $C D 8^{+} \mathrm{T}$ cells binding $\mathrm{H}-2 \mathrm{~Kb}$-SIINFEKL tetramers. (C) same as in $\mathrm{A}$ in WT and Batf3 KO mice (D) Percentage of IFN $\gamma$ producing CD4 ${ }^{+} \mathrm{T}$ cells after o.n. in vitro restimulation with I-Ab-restricted OVA $262-276$. (E) Percentage of OVA-binding germinal center $\left(G L 7^{\text {hi }}{ }^{C D} 38^{-}\right)$B cells $(\mathbf{F})$ Relative percentage of IFN $\gamma$ producing CD8 ${ }^{+}$T cells after $5 \mathrm{~h}$ in vitro restimulation with different concentrations of SIINFEKL. 100\% is the IFN $\gamma$ production after restimulation with the highest SIINFEKL concentration. (A-F) Splenocytes were taken 7 days after immunization with $1 \mu \mathrm{g}$ Ab:Ag conjugates in the presence of $25 \mu \mathrm{g}$ anti-CD40 Ab and $25 \mu \mathrm{g}$ Poly(l:C). 1 representative experiment of 2-3 experiments is shown with 4-6 mice per group with one representative dotplot of each group. Statistical analysis one-way ANOVA with bonferroni's multiple comparison test ${ }^{\star} p<0.05,{ }^{\star \star} p<0.01,{ }^{\star \star \star} p<0.001,{ }^{\star \star \star \star} p<0.0001$.

not observe any difference between targeting of protein or peptide (Figures 2A,B, Figures S3A,B). Furthermore, similar percentages of $\mathrm{CD}^{+} \mathrm{T}$ cells could produce IL-2 on day 7 and day 28 (Figures 2A right panel, C) which is described to be indicative for memory $\mathrm{T}$ cells $(33,34)$. On day 7 most
( $\sim 90 \%$ ) of the specific $\mathrm{T}$ cells that were induced with this vaccination strategy showed an effector phenotype $\left(\mathrm{CD} 44^{+}\right.$and $\left.\mathrm{CD} 2 \mathrm{~L}^{-}\right)$, while a small percentage $(\sim 10 \%)$ showed a central memory phenotype as shown by CD44 and CD62L coexpression (Figure 2D). Central memory phenotype CD8 $\mathrm{T}$ cells have been 

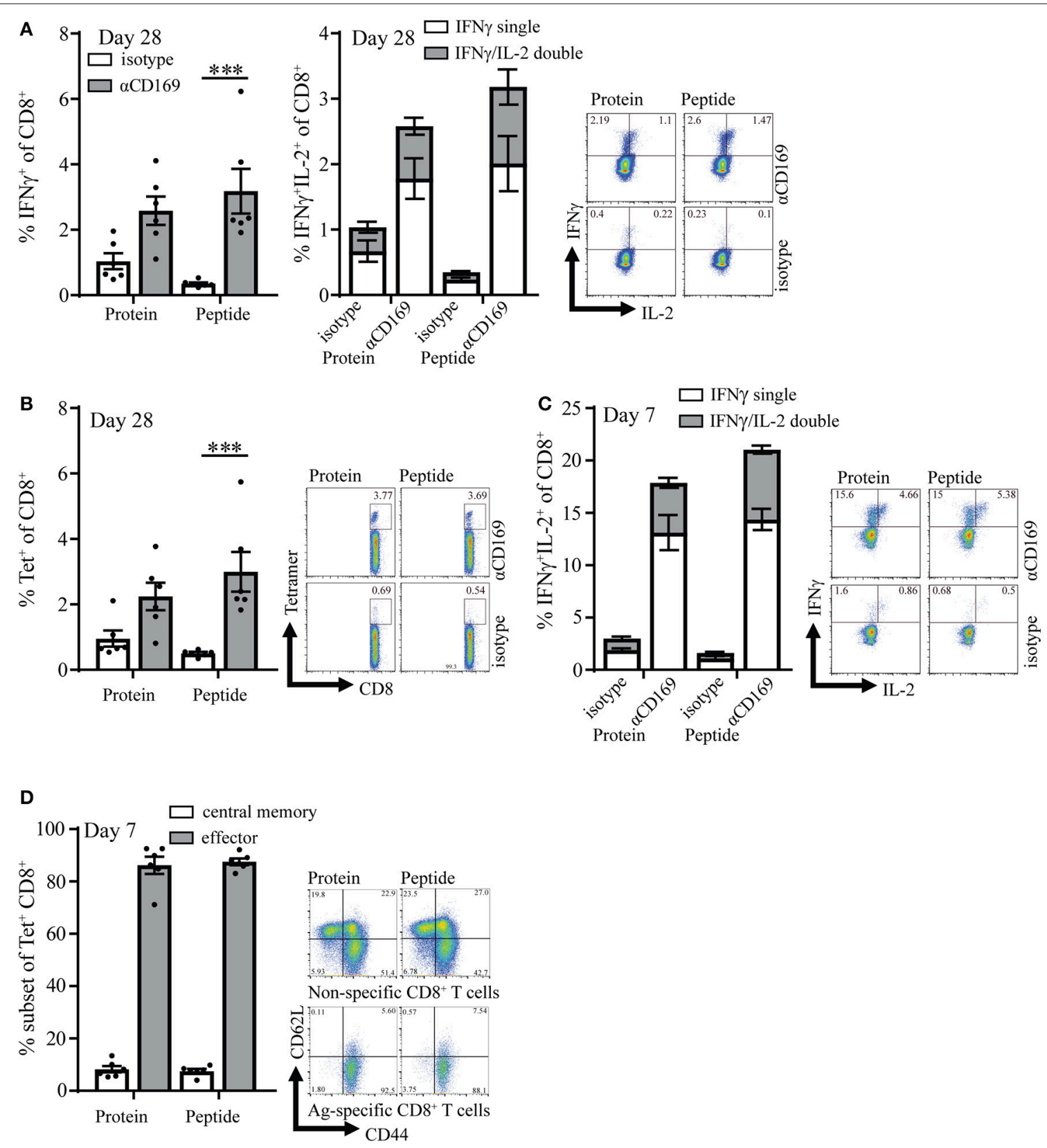

FIGURE 2 | Targeting of protein and peptide to CD169 results in long-lasting T cell responses. (A) Percentage of IFN $\gamma$ producing CD8 ${ }^{+} \mathrm{T}$ cells (left panel) and IFN $\gamma$ single and IFN $\gamma / \mathrm{IL}-2$ double producing CD8 ${ }^{+} \mathrm{T}$ cells (right panel) after $5 \mathrm{~h}$ in vitro restimulation with SIINFEKL 28 days after immunization. (B) Percentage of CD $8^{+} \mathrm{T}$ cells binding $\mathrm{H}-2 \mathrm{~Kb}-\mathrm{SIINFEKL}$ tetramers 28 days after immunization. (C) Percentage of IFN $\gamma$ single and IFN $\gamma / \mathrm{IL}-2$ double producing CD8 ${ }^{+} \mathrm{T}$ cells after $5 \mathrm{~h}$ in vitro restimulation with SIINFEKL 7 days after immunization. (D) Percentage of central memory (CD44+ $\left.{ }^{+} \mathrm{CD}_{2} \mathrm{~L}^{+}\right)$and effector $\left(\mathrm{CD} 44^{+} \mathrm{CD} 6 \mathrm{~L}^{-}\right)$antigen-specific $\mathrm{CD}^{+} \mathrm{T}^{-}$ cells at day 7 after immunization and representative dotplots for Tet $^{+}$and Tet $^{-}$CD $^{+}{ }^{+}$T cells are depicted. (A-D) 1 representative experiment of 2 is shown with 6 mice per group with a representative dotplot for each group. Statistical analysis one-way ANOVA with bonferroni's multiple comparison test *** $p<0.001$.

shown to have more proliferative capacity and better protective capacity than effector cells in infectious models (35). We did not observe differences in the generation of central memory $\mathrm{CD}^{+} \mathrm{T}$ cells when peptide and protein targeting was compared (Figure 2D).

Four weeks after the primary response the mice were boosted with SIINFEKL peptide in the presence of adjuvant to determine the capacity to raise a secondary response. Primary immunization with peptide as well as protein led to memory $\mathrm{T}$ cell responses that generated strong recall responses as shown by intracellular IFN $\gamma$ production and SIINFEKL-tetramer binding to $\mathrm{CD}^{+} \mathrm{T}$ cells (Figures $3 \mathrm{~A}, \mathbf{B}$ ). The percentage of IFN $\gamma /$ IL-2 double producing $\mathrm{CD}^{+} \mathrm{T}$ cells was similar for protein and peptide targeting and there was no difference 

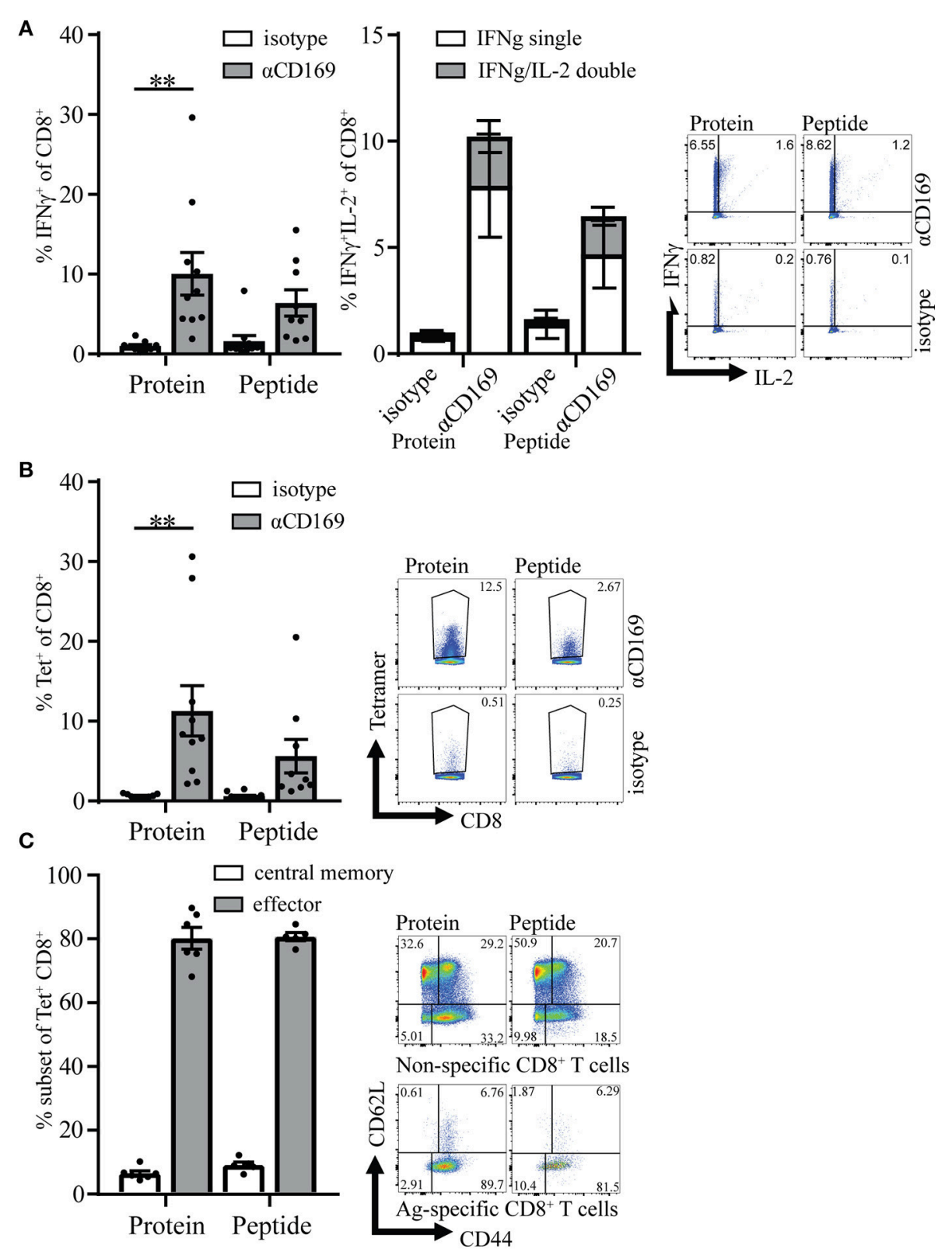

FIGURE 3 | Memory CD8 ${ }^{+}$T cell responses after targeting antigen to CD169. Mice were initially immunized with indicated Ab:Ag conjugates and the immune response was boosted 28 days later with $1 \mu \mathrm{g}$ free SIINFEKL peptide in the presence of adjuvants, 7 days after boost splenocytes were used for analysis. (A) Percentage of IFN $\gamma$ producing CD8 ${ }^{+}$T cells (left panel) and of IFN $\gamma$ single and IFN $\gamma / \mathrm{IL}-2$ double producing CD ${ }^{+} \mathrm{T}$ cells (right panel) after $5 \mathrm{~h}$ in vitro restimulation with SIINFEKL peptide. (B) Percentage of CD8 ${ }^{+} \mathrm{T}$ cells binding $\mathrm{H}-2 \mathrm{~Kb}-\mathrm{SIINFEKL}$ tetramers 28 days after immunization. (C) Percentage of central memory

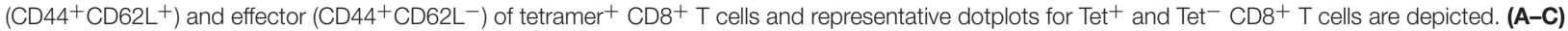
Combined results of 2 experiments is shown with 4-6 mice per group with a representative dotplot for each group. Statistical analysis one-way ANOVA with bonferroni's multiple comparison test ${ }^{\star *} p<0.01$.

in percentages of Ag specific $\mathrm{T}$ cells central memory and effector phenotype (Figures $\mathbf{3 A}$ right panel, $\mathbf{C}$ ). These results indicate that peptide as well as protein targeting to $\mathrm{CD} 169^{+}$ macrophages stimulate strong $\mathrm{CD}^{+} \mathrm{T}$ cell responses with equal potential for proliferation upon secondary encounter with antigen.

\section{Targeting of Protein and Peptide to CD169} Results in Efficient Anti-tumor T Cell

\section{Responses}

To test if the $\mathrm{CD}^{+} \mathrm{T}$ cells induced by this vaccination strategy are able to kill tumor cells in vivo, we used a therapeutic vaccination setting. Mice were injected s.c. with melanoma 
B16OVA tumor cells and 3 days later the mice were immunized with OVA protein or SIINFEKL conjugated to isotype control $\mathrm{Ab}$ or antiCD169 $\mathrm{Ab}$. Immunization with protein or peptide targeting to $\mathrm{CD} 169^{+}$macrophages was equally able to suppress outgrowth (Figures 4A,B). Since mice were sacrificed when the tumor size reached $1,000 \mathrm{~mm}^{3}$, prolonged survival was observed in those groups that received a vaccination (Figure 4C). The number of mice that had an established tumor ( during the course of the experiment was highest in non-treated and isotype-treated groups, while the number of mice that did not develop any tumor during the course of the experiment was highest in the protein targeted group. Interestingly, tumors initially grew in all the CD169-targeted groups the first 10 days (Figure 4D), but their growth was inhibited at day 10 which coincided with the peak in the $\mathrm{CD} 8^{+} \mathrm{T}$ cell response, as measured by the SIINFEKL-specific $\mathrm{CD}^{+} \mathrm{T}$ cells in the blood (Figure 4E). This was especially clear in the peptide targeted group (Figure 4D). To test if the vaccination strategy targeting protein and peptide to CD169 could result in T cell responses strong enough to suppress established tumors, mice with a visible tumor (average tumor size of $30 \mathrm{~mm}^{3}$ ) were treated 7 days after tumor inoculation. The progression of established tumors into a fast-growing tumor was suppressed after targeting protein or peptide to CD169 (Figure 4F, Figures S4A-C). Together these data show that the induction of SIINFEKL-specific $\mathrm{CD}^{+} \mathrm{T}$ cell responses by either protein or peptide vaccination results in efficient control of tumor outgrowth.

\section{DISCUSSION}

Vaccination approaches to induce anti-tumor $\mathrm{CD}^{+} \mathrm{T}$ cell responses should fulfill a number of requirements. First of all, sufficient numbers of effector $\mathrm{CD}^{+} \mathrm{T}$ cells should be activated to eradicate the existing primary tumor and/or metastases. Adoptive $\mathrm{T}$ cell transfer studies in both patients and mouse models have indicated that the number of transferred $\mathrm{T}$ cells is correlated with tumor regression (36, 37). Similarly, the number of $\mathrm{T}$ cells induced by vaccination approaches is predictive for their capacity to induce regression of existing tumors (38). Secondly, the differentiation stage of the activated $\mathrm{CD}^{+} \mathrm{T}$ cells is important. Central memory or memory stem cell $\mathrm{T}$ cells are better in eliminating tumors than terminal differentiated effector cells that are obtained by multiple rounds of restimulation $(36,39)$. Thirdly, vaccination approaches should induce $\mathrm{T}$ cells with the capacity to efficiently home to tumors, such as resident memory $\mathrm{T}$ cells $(40,41)$ and should not induce $\mathrm{T}$ cells that home back to the vaccination site $(42,43)$. Finally, vaccination should result in long-lived $\mathrm{CD} 8^{+} \mathrm{T}$ cell memory that will continuously eliminate outgrowth of tumor cells. Long term $\mathrm{CD}^{+} \mathrm{T}$ cell memory is critically dependent on CD4 ${ }^{+} \mathrm{T}$ cell help. Activation of $\mathrm{CD}^{+} \mathrm{T}$ cells in the absence of CD4 T cells can result in effector cells when sufficient inflammation is present, but these cells have defects in restimulation, do not generate secondary responses, and are called "helpless" T cells (44-46). Vaccination approaches using only MHC class I restricted tumor epitopes may have the risk of not generating long-term $\mathrm{CD} 8^{+} \mathrm{T}$ cell memory.
In our studies, we have evaluated the targeting of OVA protein and peptide antigen to $\mathrm{CD}_{169^{+}}$macrophages to induce antitumor $\mathrm{CD}^{+} \mathrm{T}$ cell responses. We observed very high frequencies of OVA-specific $\mathrm{CD}^{+} \mathrm{T}$ cells (more than $10 \%$ of total $\mathrm{CD}^{+}$ $\mathrm{T}$ cells) after just one intravenous vaccination and targeting to $\mathrm{CD}_{169^{+}}$macrophages was as good as targeting to DEC205 ${ }^{+}$ dendritic cells. This excellent induction of $\mathrm{CD} 8^{+} \mathrm{T}$ cell responses, could potentially be due to the fact that $\mathrm{CD} 169^{+}$very efficiently filter the blood and bind targeting antibodies. In addition, one of the unique characteristics of $\mathrm{CD}_{169^{+}}$macrophages is the capacity to preserve intact antigen on their surface for days, which enables presentation and transfer to B cells and DCs $(11,13,14,16)$. Together these characteristics may enhance the amount of antigen presented during a longer period of time than that obtained during direct targeting to DCs. The activation of high numbers of $\mathrm{CD}^{+} \mathrm{T}$ cells in just one immunization is also beneficial for their differentiation status as multiple rounds of $\mathrm{Ag}$ encounter lead to terminally differentiated cells with decreased potential for tumor regression (36).

Although $\mathrm{CD}^{+}{ }^{+} \mathrm{T}$ cells specific for OVA were not generated in the peptide vaccination and are considered essential for longterm $\mathrm{CD}^{+} \mathrm{T}$ cell memory, we did not observe differences in the percentage of IL-2 producing or central memory phenotype $\mathrm{CD}^{+} \mathrm{T}$ cells after priming and restimulation. Also similar memory $\mathrm{CD}^{+} \mathrm{T}$ cell responses were generated when peptide and protein targeting were compared. Apparently our vaccination did not lead to a defect in memory $\mathrm{T}$ cell generation when peptides were used for targeting which could potentially be explained by two factors. First of all, we utilized a very strong adjuvant that mimics CD4 T cell help (anti-CD40 plus poly I:C) which makes additional CD4 $\mathrm{T}$ cell help dispensable (47-49). Indeed $\mathrm{CD}^{+} \mathrm{T}$ cell responses are efficiently elicited in MHC class IIdeficient mice with our vaccination approach, demonstrating the dispensable role for $\mathrm{CD} 4^{+} \mathrm{T}$ cells with this adjuvant (data not shown). Several clinical trials in which agonistic anti-CD40 $\mathrm{Ab}$ is tested for its effect in solid tumors such as melanoma, non-small cell lung cancer and pancreatic duct adenocarcinoma sometimes in combination with checkpoint inhibitors have been started. The combination of agonistic anti-CD40 Ab with a vaccination strategy has not yet been explored in clinical trials and may be considered for neoantigen peptide vaccination strategies.

Secondly, we used rat antibodies to target our antigens to the $\mathrm{CD} 169^{+}$macrophages. These rat antibodies are likely to be immunogenic in mice and could contain helper epitopes for $\mathrm{CD}^{+}{ }^{+} \mathrm{T}$ cells as has been described for anti-Clec9A/DNGR-1 antibodies (50). Cloning of the CD169-specific antibodies and the generation of recombinant mouse antibodies would be necessary to exclude this additional immunogenicity. However, although potential rat IgG2a-specific $\mathrm{CD}^{+}{ }^{+} \mathrm{T}$ cells could be induced in the vaccination procedure, these helper $\mathrm{CD} 4^{+} \mathrm{T}$ cells were not involved in the OVA-specific anti-tumor response.

Both peptide and protein targeting to CD169 stimulated potent anti-tumor $\mathrm{CD}^{+} \mathrm{T}$ cell responses that were as efficient to prevent outgrowth of B16-OVA melanoma cells, indicating that the generated OVA specific $\mathrm{CD}^{+} \mathrm{T}$ cell homed to the tumor. Interestingly, Batf3-dependent $\mathrm{CDC1}$ have been shown to 


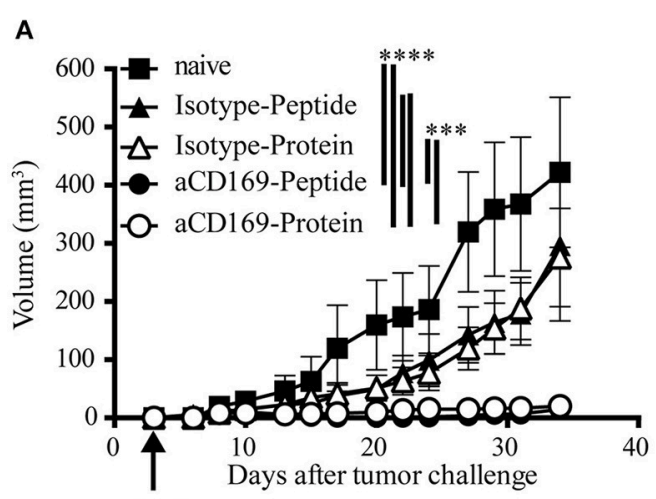

day 3

B
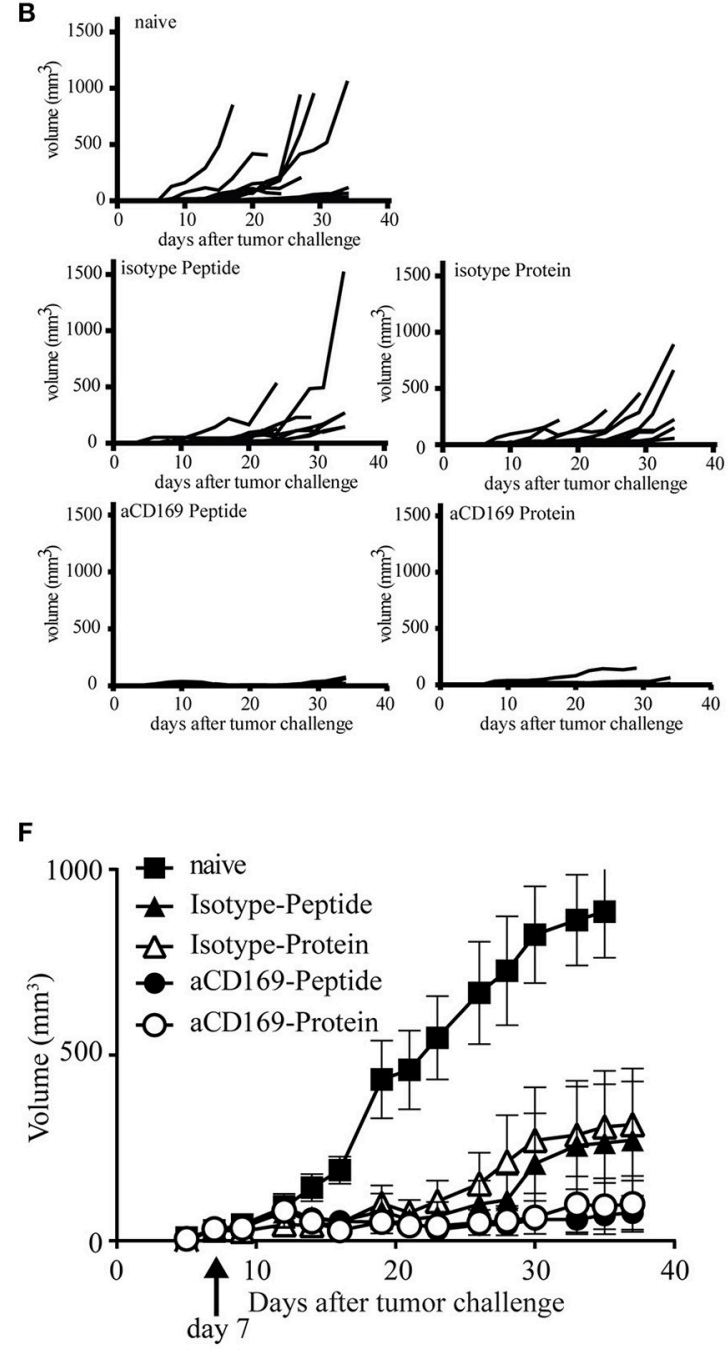

days atter tumor challenge
C
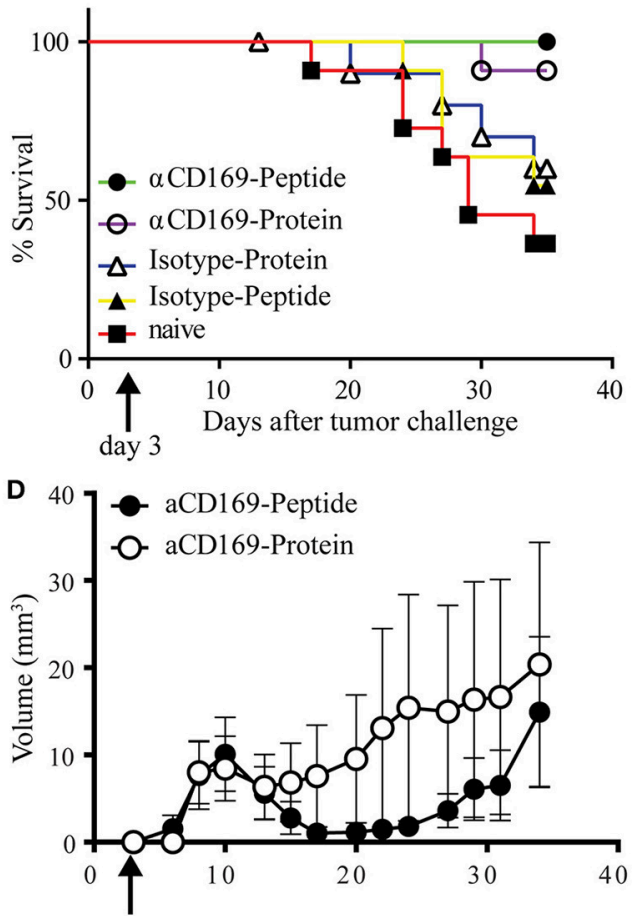

day 3

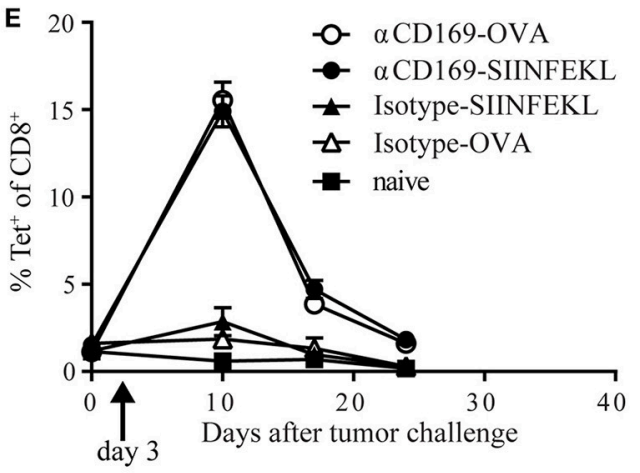

FIGURE 4 | Targeting of protein and peptide to CD169 results in the induction of tumor reactive T cell responses. (A-E) Mice were inoculated with 200,000 B160VA tumor cells at day 0 , on day 3 mice were immunized with indicated Ab:Ag conjugates in the presence of anti-CD40 Ab and Poly(l:C). Tumor size was monitored three times a week and mice were sacrificed based on physical appearance or tumor size. (A) Tumor size on different days after tumor inoculation, mean \pm SEM is shown. Two-way ANOVA with Bonferroni correction comparing all groups on the last day of the experiment, only significant differences are depicted. (B) Tumor size per group of each mouse after tumor inoculation (C) Percentage of surviving mice on indicated days after tumor inoculation. (D) Tumor volume as in (A), but only showing the groups treated with the anti-CD169:Ag conjugates on a fitting scale. (E) Percentage of CD8 ${ }^{+} \mathrm{T}$ cells binding $\mathrm{H}-2 \mathrm{~Kb}-\mathrm{SIINFEKL}$ tetramers at indicated time points during the tumor experiment. (A-E) One experiment with 11 mice per group is shown. (F) Same as in (A), with treatment on day 7 after tumor cell inoculation, when all mice had a visible tumor. Data of one experiment with 11-12 mice per group is shown. Statistical analysis one-way ANOVA with bonferroni's multiple comparison test ${ }^{* * *} p<0.001,{ }^{* * * *} p<0.0001$. 
promote the generation of tissue resident memory T cells $(40,51)$. Batf3-dependent $\mathrm{cDC} 1$ also are known to facilitate $\mathrm{CD}^{+}{ }^{+} \mathrm{T}$ cell help and efficient long-term memory $\mathrm{CD}^{+} \mathrm{T}$ cell generation $(52,53)$. Apparently, antigen presentation by $\mathrm{cDC} 1$ is crucial for optimal memory $\mathrm{CD} 8^{+} \mathrm{T}$ cell responses with the capacity to home into tissues. We previously showed that targeting protein antigens to $\mathrm{CD} 169^{+}$macrophages transferred antigen to $\mathrm{CDC} 1$ and cross-primed $\mathrm{CD}^{+} \mathrm{T}$ cells $(14,16)$. Here, we show that also peptide targeted to $\mathrm{CD} 169^{+}$macrophages required Batf3dependent $\mathrm{cDC} 1$ s to stimulate $\mathrm{CD}^{+} \mathrm{T}$ cell responses, which may explain the observed similar capacity of peptide and protein antigens to stimulate effector, memory, recall $\mathrm{CD}^{+} \mathrm{T}$ cell responses and the capacity to prevent tumor outgrowth.

A recent study has demonstrated that mouse tumors contain increased numbers of $\mathrm{CD} 69^{+}$antigen presenting cells with characteristics of both DCs and macrophages that are able to home to lymph nodes and to cross-present tumor cell-derived Ag (54). Since conventional DC numbers may be limiting in tumors, Ag targeting to $\mathrm{CD} 169^{+}$cells in tumor-bearing individuals may potentially have more impact than Ag targeting to conventional DCs. Although the structure of the human spleen is different from mouse spleen and lacks a marginal zone, CD169-expressing macrophages are found in perifollicular sheaths surrounding small capillaries, also located in close contact with B cells (28). These structures would also be optimally suited for capture of antigens from blood by macrophages and presentation to B cells

\section{REFERENCES}

1. Gray EE, Cyster JG. Lymph node macrophages. J Innate Immun. (2012) 4:424-36. doi: 10.1159/000337007

2. Mebius RE, Kraal G. Structure and function of the spleen. Nat Rev Immunol. (2005) 5:606-16. doi: 10.1038/nri1669

3. Barral P, Polzella P, Bruckbauer A, van Rooijen N, Besra GS, Cerundolo $\mathrm{V}$, et al. CD169(+) macrophages present lipid antigens to mediate early activation of iNKT cells in lymph nodes. Nat Immunol. (2010) 11:303-12. doi: $10.1038 /$ ni.1853

4. Garcia Z, Lemaitre F, van RN, Albert ML, Levy Y, Schwartz O, et al. Subcapsular sinus macrophages promote NK cell accumulation and activation in response to lymph-borne viral particles. Blood (2012) 120:4744-50. doi: 10.1182/blood-2012-02-408179

5. Kastenmuller W, Torabi-Parizi P, Subramanian N, Lammermann T, Germain RN. A spatially-organized multicellular innate immune response in lymph nodes limits systemic pathogen spread. Cell (2012) 150:1235-48. doi: 10.1016/j.cell.2012.07.021

6. Kawasaki N, Vela JL, Nycholat CM, Rademacher C, Khurana A, van RN, et al. Targeted delivery of lipid antigen to macrophages via the CD169/sialoadhesin endocytic pathway induces robust invariant natural killer T cell activation. Proc Natl Acad Sci USA. (2013) 110:7826-31. doi: 10.1073/pnas.1219888110

7. Zhang Y, Roth TL, Gray EE, Chen H, Rodda LB, Liang Y, et al. Migratory and adhesive cues controlling innate-like lymphocyte surveillance of the pathogen-exposed surface of the lymph node. Elife (2016) 5:e18156. doi: 10.7554/eLife.18156

8. Berney C, Herren S, Power CA, Gordon S, Martinez-Pomares L, KoscoVilbois MH. A member of the dendritic cell family that enters B cell follicles and stimulates primary antibody responses identified by a mannose receptor fusion protein. J Exp Med. (1999) 190:851-60. doi: 10.1084/jem.190.6.851

9. Carrasco YR, Batista FD. B cells acquire particulate antigen in a macrophagerich area at the boundary between the follicle and the subcapsular sinus of the lymph node. Immunity (2007) 27:160-71. doi: 10.1016/j.immuni.2007.06.007

10. Junt $T$, Moseman EA, Iannacone $M$, Massberg S, Lang PA, Boes $M$, et al. Subcapsular sinus macrophages in lymph nodes clear lymph-borne and potentially also to DCs. Strategies that target to human CD169 molecules may therefore also be efficient in directing antigens to the right lymphoid structure for the activation of antitumor immune responses and should be further explored as a vaccination strategy in humans.

\section{AUTHOR CONTRIBUTIONS}

DvD, HV, and $\mathrm{JdH}$ experimental design. Experiments were conducted by DvD, HV, MR, EB, LH, KO, and JG. HK synthesized conjugates. Data analysis by DvD, HV, and MR. The manuscript was written by $\mathrm{JdH}$ and $\mathrm{DvD}$ and edited by all authors.

\section{ACKNOWLEDGMENTS}

This work was supported by grants from the Dutch Cancer Society (VU2009-4504 and VU2013-5940) and by VUmc CCA grant 2015-5-22 to JdH. We thank J. P. Middelberg, C. Prins and R. van der Laan for animal care.

\section{SUPPLEMENTARY MATERIAL}

The Supplementary Material for this article can be found online at: https://www.frontiersin.org/articles/10.3389/fimmu. 2018.01997/full\#supplementary-material

viruses and present them to antiviral B cells. Nature (2007) 450:110-4. doi: 10.1038/nature06287

11. Phan TG, Green JA, Gray EE, Xu Y, Cyster JG. Immune complex relay by subcapsular sinus macrophages and noncognate B cells drives antibody affinity maturation. Nat Immunol. (2009) 10:786-93. doi: 10.1038/ni.1745

12. Phan TG, Grigorova I, Okada T, Cyster JG. Subcapsular encounter and complement-dependent transport of immune complexes by lymph node B cells. Nat Immunol. (2007) 8:992-1000. doi: 10.1038/ni1494

13. Veninga H, Borg EG, Vreeman K, Taylor PR, Kalay H, van KY, et al. Antigen targeting reveals splenic CD169+ macrophages as promoters of germinal center B-cell responses. Eur J Immunol. (2015) 45:747-57. doi: 10.1002/eji.201444983

14. Backer R, Schwandt T, Greuter M, Oosting M, Jungerkes F, Tuting T, et al. Effective collaboration between marginal metallophilic macrophages and CD8+ dendritic cells in the generation of cytotoxic T cells. Proc Natl Acad Sci USA. (2010) 107:216-21. doi: 10.1073/pnas.0909541107

15. Bernhard CA, Ried C, Kochanek S, Brocker T. CD169+ macrophages are sufficient for priming of CTLs with specificities left out by crosspriming dendritic cells. Proc Natl Acad Sci USA. (2015) 112:5461-6. doi: $10.1073 /$ pnas. 1423356112

16. van Dinther D, Veninga H, Iborra S, Borg EGF, Hoogterp L, Olesek $\mathrm{K}$, et al. Functional CD169 on macrophages mediates interaction with dendritic cells for CD8(+) T cell cross-priming. Cell Rep. (2018) 22:1484-95. doi: 10.1016/j.celrep.2018.01.021

17. Postow MA, Chesney J, Pavlick AC, Robert C, Grossmann K, McDermott D, et al. Nivolumab and ipilimumab versus ipilimumab in untreated melanoma. N Engl J Med. (2015) 372:2006-17. doi: 10.1056/NEJMoa1414428

18. Sharma P, Allison JP. The future of immune checkpoint therapy. Science (2015) 348:56-61. doi: 10.1126/science.aaa8172

19. Melief CJ, van Hall T, Arens R, Ossendorp F, van der Burg SH. Therapeutic cancer vaccines. J Clin Invest. (2015) 125:3401-12. doi: 10.1172/JCI80009

20. Bonifaz LC, Bonnyay DP, Charalambous A, Darguste DI, Fujii S, Soares H, et al. In vivo targeting of antigens to maturing dendritic cells via the DEC205 receptor improves T cell vaccination. J Exp Med. (2004) 199:815-24. doi: $10.1084 /$ jem. 20032220 
21. Caminschi I, Proietto AI, Ahmet F, Kitsoulis S, Shin Teh J, Lo JC, et al. The dendritic cell subtype-restricted C-type lectin Clec9A is a target for vaccine enhancement. Blood (2008) 112:3264-73. doi: 10.1182/blood-2008-05-155176

22. Sancho D, Mourao-Sa D, Joffre OP, Schulz O, Rogers NC, Pennington DJ, et al. Tumor therapy in mice via antigen targeting to a novel, DC-restricted C-type lectin. J Clin Invest. (2008) 118:2098-110. doi: 10.1172/JCI34584

23. van Dinther D, Stolk DA, van de Ven R, van Kooyk Y, de Gruijl TD, den Haan JMM. Targeting C-type lectin receptors: a high-carbohydrate diet for dendritic cells to improve cancer vaccines. J Leukoc Biol. (2017) 102:1017-34. doi: 10.1189/jlb.5MR0217-059RR

24. Ohnishi K, Komohara Y, Saito Y, Miyamoto Y, Watanabe M, Baba H, et al. CD169-positive macrophages in regional lymph nodes are associated with a favorable prognosis in patients with colorectal carcinoma. Cancer Sci. (2013) 104:1237-44. doi: 10.1111/cas.12212

25. Ohnishi K, Yamaguchi M, Erdenebaatar C, Saito F, Tashiro H, Katabuchi $\mathrm{H}$, et al. Prognostic significance of CD169-positive lymph node sinus macrophages in patients with endometrial carcinoma. Cancer Sci. (2016) 107:846-52. doi: 10.1111/cas.12929

26. Saito Y, Ohnishi K, Miyashita A, Nakahara S, Fujiwara Y, Horlad H, et al. Prognostic significance of CD169+ lymph node sinus macrophages in patients with malignant melanoma. Cancer Immunol Res. (2015) 3:1356-63. doi: 10.1158/2326-6066.CIR-14-0180

27. Steiniger B, Barth P, Herbst B, Hartnell A, Crocker PR. The speciesspecific structure of microanatomical compartments in the human spleen: strongly sialoadhesin-positive macrophages occur in the perifollicular zone, but not in the marginal zone. Immunology (1997) 92:307-16. doi: 10.1046/j.1365-2567.1997.00328.x

28. Steiniger BS, Seiler A, Lampp K, Wilhelmi V, Stachniss V. B lymphocyte compartments in the human splenic red pulp: capillary sheaths and periarteriolar regions. Histochem Cell Biol. (2014) 141:507-18. doi: 10.1007/s00418-013-1172-z

29. Bonifaz L, Bonnyay D, Mahnke K, Rivera M, Nussenzweig MC, Steinman RM. Efficient targeting of protein antigen to the dendritic cell receptor DEC-205 in the steady state leads to antigen presentation on major histocompatibility complex class I products and peripheral CD8+T cell tolerance. J Exp Med. (2002) 196:1627-38. doi: 10.1084/jem.20021598

30. Laidlaw BJ, Craft JE, Kaech SM. The multifaceted role of CD4(+) T cells in CD8(+) T cell memory. Nat Rev Immunol. (2016) 16:102-11. doi: 10.1038/nri.2015.10

31. Leon B, Ballesteros-Tato A, Randall TD, Lund FE. Prolonged antigen presentation by immune complex-binding dendritic cells programs the proliferative capacity of memory CD8 T cells. J Exp Med. (2014) 211:1637-55. doi: 10.1084/jem.20131692

32. Williams MA, Holmes BJ, Sun JC, Bevan MJ. Developing and maintaining protective CD8+ memory T cells. Immunol Rev. (2006) 211:146-53. doi: 10.1111/j.0105-2896.2006.00389.x

33. Boyman $\mathrm{O}$, Cho $\mathrm{JH}$, Sprent J. The role of interleukin-2 in memory CD8 cell differentiation. Adv Exp Med Biol. (2010) 684:28-41. doi: 10.1007/978-1-4419-6451-9_3

34. Feau S, Arens R, Togher S, Schoenberger SP. Autocrine IL-2 is required for secondary population expansion of CD8(+) memory T cells. Nat Immunol. (2011) 12:908-13. doi: 10.1038/ni.2079

35. Wherry EJ, Teichgraber V, Becker TC, Masopust D, Kaech SM, Antia R, et al. Lineage relationship and protective immunity of memory CD8 T cell subsets. Nat Immunol. (2003) 4:225-34. doi: 10.1038/ni889

36. Klebanoff CA, Gattinoni L, Palmer DC, Muranski P, Ji Y, Hinrichs CS, et al. Determinants of successful CD8+ T-cell adoptive immunotherapy for large established tumors in mice. Clin Cancer Res. (2011) 17:5343-52. doi: 10.1158/1078-0432.CCR-11-0503

37. Rosenberg SA, Yang JC, Sherry RM, Kammula US, Hughes MS, Phan GQ, et al. Durable complete responses in heavily pretreated patients with metastatic melanoma using T-cell transfer immunotherapy. ClinCancer Res. (2011) 17:4550-7. doi: 10.1158/1078-0432.CCR-11-0116

38. van Duikeren S, Arens R. Predicting the efficacy of cancer vaccines by evaluating T-cell responses. Oncoimmunology (2013) 2:e22616. doi: $10.4161 /$ onci.22616

39. Gattinoni L, Klebanoff CA, Restifo NP. Paths to stemness: building the ultimate antitumour T cell. Nat Rev Cancer (2012) 12:671-84. doi: $10.1038 / \operatorname{nrc} 3322$
40. Enamorado M, Iborra S, Priego E, Cueto FJ, Quintana JA, Martinez-Cano S, et al. Enhanced anti-tumour immunity requires the interplay between resident and circulating memory CD8(+) T cells. Nat Commun. (2017) 8:16073. doi: $10.1038 /$ ncomms 16073

41. Jacquelot N, Enot DP, Flament C, Vimond N, Blattner C, Pitt JM, et al. Chemokine receptor patterns in lymphocytes mirror metastatic spreading in melanoma. J Clin Invest. (2016) 126:921-37. doi: 10.1172/JCI80071

42. Hailemichael Y, Dai Z, Jaffarzad N, Ye Y, Medina MA, Huang XF, et al. Persistent antigen at vaccination sites induces tumor-specific CD8(+) $\mathrm{T}$ cell sequestration, dysfunction and deletion. Nat Med. (2013) 19:465-72. doi: $10.1038 / \mathrm{nm} .3105$

43. Overwijk WW. Cancer vaccines in the era of checkpoint blockade: the magic is in the adjuvant. Curr Opin Immunol. (2017) 47:103-9. doi: 10.1016/j.coi.2017.07.015

44. Janssen EM, Lemmens EE, Wolfe T, Christen U, von Herrath MG, Schoenberger SP. CD4+ $\mathrm{T}$ cells are required for secondary expansion and memory in CD8+ $\mathrm{T}$ lymphocytes. Nature (2003) 421:852-6. doi: $10.1038 /$ nature 01441

45. Shedlock DJ, Shen H. Requirement for CD4 T cell help in generating functional CD8 T cell memory. Science (2003) 300:337-9. doi: $10.1126 /$ science. 1082305

46. Sun JC, Bevan MJ. Defective CD8T cell memory following acute infection without CD4 T cell help. Science (2003) 300:339-42. doi: $10.1126 /$ science. 1083317

47. Bennett SR, Carbone FR, Karamalis F, Flavell RA, Miller JF, Heath WR. Help for cytotoxic-T-cell responses is mediated by CD40 signalling. Nature (1998) 393:478-80. doi: 10.1038/30996

48. Ridge JP, Di Rosa F, Matzinger P. A conditioned dendritic cell can be a temporal bridge between a CD4+ T-helper and a T-killer cell. Nature (1998) 393:474-8. doi: 10.1038/30989

49. Schoenberger SP, Toes RE, van der Voort EI, Offringa R, Melief CJ. T-cell help for cytotoxic $\mathrm{T}$ lymphocytes is mediated by CD40CD40L interactions. Nature (1998) 393:480-3. doi: 10.1038/ 31002

50. Li J, Ahmet F, Sullivan LC, Brooks AG, Kent SJ, De RoseR, et al. Antibodies targeting Clec9A promote strong humoral immunity without adjuvant in mice and non-human primates. Eur J Immunol. (2015) 45:854-64. doi: 10.1002/eji.201445127

51. Iborra S, Martinez-Lopez M, Khouili SC, Enamorado M, Cueto FJ, Conde-Garrosa R, et al. Optimal generation of tissue-resident but not circulating memory $\mathrm{T}$ cells during viral infection requires crosspriming by DNGR-1+ dendritic cells. Immunity (2016) 45:847-60. doi: 10.1016/j.immuni.2016.08.019

52. Eickhoff S, Brewitz A, Gerner MY, Klauschen F, Komander K, Hemmi H, et al. Robust anti-viral immunity requires multiple distinct $\mathrm{T}$ cell-dendritic cell interactions. Cell (2015) 162:1322-37. doi: 10.1016/j.cell.2015.08.004

53. Hor JL, Whitney PG, Zaid A, Brooks AG, Heath WR, Mueller SN. Spatiotemporally distinct interactions with dendritic cell subsets facilitates $\mathrm{CD} 4+$ and $\mathrm{CD} 8+\mathrm{T}$ cell activation to localized viral infection. Immunity (2015) 43:554-65. doi: 10.1016/j.immuni.2015. 07.020

54. Sheng J, Chen Q, Soncin I, Ng SL, Karjalainen K, Ruedl C. A discrete subset of monocyte-derived cells among typical conventional type 2 dendritic cells can efficiently cross-present. Cell Rep. (2017) 21:1203-14. doi: 10.1016/j.celrep.2017.10.024

Conflict of Interest Statement: The authors declare that the research was conducted in the absence of any commercial or financial relationships that could be construed as a potential conflict of interest.

The reviewer PVE and handling Editor declared their shared affiliation.

Copyright (C) 2018 van Dinther, Veninga, Revet, Hoogterp, Olesek, Grabowska, Borg Kalay, van Kooyk and den Haan. This is an open-access article distributed under the terms of the Creative Commons Attribution License (CC BY). The use, distribution or reproduction in other forums is permitted, provided the original author(s) and the copyright owner(s) are credited and that the original publication in this journal is cited, in accordance with accepted academic practice. No use, distribution or reproduction is permitted which does not comply with these terms. 